Artigos

Volume 9 - 2019|n. 13

\title{
O Gasto Aluno-Ano no Estado do Paraná em 2017: o contraste dos valores máximo e mínimo
}

\author{
Isabella de Meira Araujo \\ Universidade Federal do Paraná (UFPR), Curitiba/PR - Brasil
}

\section{Resumo}

O presente artigo objetiva a análise do gasto por aluno no estado do Paraná, no ano de 2017, principalmente no que tange ao valor máximo e mínimo encontrado nos municípios de Itaipulândia e Colombo, respectivamente. Para isso, utilizaram-se dados do Tesouro Nacional extraídos do arquivo Finanças do Brasil (Finbra), dados do Sistema de Informações sobre Orçamentos Públicos em Educação (Siope) e do Censo Escolar. Verificou-se que os dois municípios ficaram com valores positivos nas receitas do FUNDEB e conseguiram aplicar os valores mínimos legais para a educação. No entanto, devido aos Royalties recebidos da Itaipu Binacional, o município de Itaipulândia consegue investir mais em educação, tendo, até mesmo, um programa de subsídio à Educação Superior. Enquanto que, Colombo, possui baixo desenvolvimento econômico e arrecadação tributária limitada, o que acarreta diretamente no baixo gasto aluno-ano.

Palavras-chave: Financiamento da Educação. Gasto Aluno-Ano. FUNDEB. Paraná, Brasil.

\section{Expenditure Student-Year in the State of Parana in 2017: the contrast of the maximum and minimum values}

\begin{abstract}
This article aims to analyze the expenditure per student in the state of Paraná in 2017, mainly regarding the maximum and minimum amount found in the municipalities of Itaipulândia and Colombo, respectively. For this purpose, it was used data from the National Treasury extracted from the Finance of Brazil (Finbra) archive, data from the Information System about Public Budgets in Education (Siope), as well as data from the School Census. It was found that the two municipalities had positive balance in FUNDEB revenues and were able to apply the legal minimum values for education. However, due to the royalties received from Itaipu Binacional, the municipality of Itaipulândia was able to invest more in education, even having a program to subsidize college education for its citizens. In its turn, Colombo has lower economic development and limited tax collection, which directly entails the amount spent per year.
\end{abstract}

Keywords: Funding of Education. Expenditure Student-Year. FUNDEB. Paraná, Brazil. 
O Gasto Aluno-Ano no Estado do Paraná em 2017

\section{Introdução}

A estrutura do financiamento da educação brasileira não é algo simples: é um processo complexo que possui fontes variadas de recursos, no qual os entes federados dependem uns dos outros e da sua própria arrecadação para poder custear os gastos educacionais. Discutir sobre o gasto aluno requer uma compreensão mais ampla desse processo, no que tange a discutir sobre a vinculação da receita de impostos, presente desde a constituição de 1934 (mas com interrupções ao longo dos anos), e também sobre a política de fundos, a qual representa um modelo de subvinculação de recursos, implementado nacionalmente com o Fundo de Manutenção e Desenvolvimento do Ensino Fundamental e de Valorização do Magistério (FUNDEF) e aprofundado com o seu sucessor, o Fundo de Manutenção e Desenvolvimento da Educação Básica e de Valorização dos Profissionais da Educação (FUNDEB).

A redistribuição de recursos, feita no contexto da política de fundos, é voltada a garantir, em tese, a equidade dos investimentos em educação, visando a redistribuição dos recursos, levando em conta o número de matrículas das redes de ensino. No entanto, a política de fundos, ainda que represente avanços significativos, não conseguiu a garantia de um custo por aluno que garanta a qualidade. Ademais, ainda há muitas disparidades nos valores investidos em diferentes municípios, o que acentua desigualdades inter-regionais e locais (OLIVEIRA, 1999).

O estado do Paraná, mesmo sob a lógica da vinculação de recursos desde 1988, não obteve recursos complementares da União em nenhum ano. Em tese, pode-se dizer que o estado paranaense possui arrecadação tributária suficiente para financiar sua rede de ensino.

No entanto, estudos anteriores já demonstraram os problemas da ausência da União ao evidenciar a manutenção das desigualdades inter-regionais no interior do estado, uma vez que municípios com condições econômicas melhores apresentam melhores gastos alunoano, enquanto municípios com condições economicamente precárias evidenciam piores valores de investimentos em educação (GOUVEIA; SILVA, 2012).

Nesse sentido, o presente artigo objetiva analisar o gasto por aluno no estado do Paraná no ano de 2017, principalmente no que condiz ao valor máximo e mínimo encontrado nos municípios de Itaipulândia e Colombo, respectivamente. Para isso, utilizaram-se dados do Tesouro Nacional, extraídos do arquivo Finanças do Brasil (Finbra), dados do Sistema de Informações sobre Orçamentos Públicos em Educação (Siope) e do Censo Escolar.

\section{Financiamento da Educação Básica no Brasil: breve contexto}

A alocação obrigatória de recursos é parte importante para a garantia do direito à educação. Desde a Constituição Brasileira de 1934, com algumas interrupções, a vinculação de recursos para a educação vem sendo estabelecida por meio de percentual mínimo resultante da arrecadação de impostos. Mas, somente na Constituição Federal de 1988, no artigo 212, ficou estipulado que a União deve aplicar anualmente nunca menos de $18 \%$ da receita de impostos, inclusive transferências, na Manutenção e o Desenvolvimento do Ensino (MDE), enquanto estados, municípios e Distrito Federal devem aplicar o mínimo de $25 \%$ da receita de impostos em MDE (BRASIL, 1988). Tal ação ampliou a autonomia dos estados e municípios (FARENZENA, 2006). 
Além dessa, outra fonte importante de financiamento é o Salário-Educação, o qual é proveniente de uma contribuição social calculada com base na alíquota de $2,5 \%$ sobre o valor total da folha de contribuição das empresas. A divisão dos recursos é estabelecida da seguinte maneira:

$10 \%$ são administrados diretamente pelo FNDE em programas federais para a educação básica e os $90 \%$ são divididos em 3 partes - cota federal, também destinadas a programas federais, cotas estaduais e municipais repassados segundo o número de alunos de cada localidade (SOUZA; GOUVEIA; TAVARES, 2011, p. 100).

Entretanto, ainda que a vinculação cumpra importante papel de propiciar um mínimo de estabilidade financeira ao financiamento da educação, esse mecanismo não trouxe garantia de financiamento adequado, nem transparência e equidade no uso dos recursos. Há grande desigualdade na arrecadação da receita de impostos entre diferentes estados e municípios brasileiros (ADRIÃO, 2014).

Diante do paradoxo do contexto das políticas de restrição de gastos da União, durante os anos 1990, e a necessidade de enfrentamento das desigualdades de condições tributárias e suas consequências nas condições de financiamento, fez-se necessário a política de fundos. O artigo 60 do Ato das Disposições Constitucionais Transitórias (ADCT) previa a criação de fundos, que foram implementados, inicialmente, por meio da EC n. 14 de 12 de setembro de 1996, com a criação do Fundo de Manutenção e Desenvolvimento do Ensino Fundamental ${ }^{1}$ e de Valorização do Magistério (FUNDEF). Sua regulamentação se deu pela Lei 9.424/1996. O fundo teve vigência em todos os estados e municípios de $1^{\circ}$ de janeiro de 1998 a 31 de dezembro de 2006 (BRASIL, 1996b).

Esse fundo foi criado como um mecanismo contábil, uma forma de redistribuir o dinheiro dentro de cada estado da federação, portanto não significou aporte de recursos novos (o contexto dos anos 1990 explica por que não houve dinheiro novo, com exceção dos poucos que receberam algum aporte no início do fundo). O retorno de tais recursos aos governos municipais e estaduais ficou condicionado ao número de alunos matriculados no ensino fundamental regular em cada rede pública, tendo como parâmetro o Censo Escolar do ano anterior.

Além disso, seus recursos deviam ser empregados exclusivamente na manutenção e desenvolvimento do ensino fundamental regular, com o mínimo de $60 \%$ destinado ao pagamento de professores em efetivo exercício no magistério. Também foi estipulado um valor mínimo nacional por aluno a cada ano. O cálculo do mínimo se dava pela divisão da soma de recursos de todos os estados pelo número de matrículas no ensino fundamental público regular em âmbito nacional. Se algum estado não conseguisse atingir esse mínimo, receberia complementação da União, como bem coloca Souza, Gouveia e Tavares (2011). No entanto, essa regra não foi cumprida e pode-se dizer que esse foi um dos principais problemas do FUNDEF.

Em razão de que todas as etapas e modalidades precisam contar com recursos financeiros, foi criado em 2006, pela Emenda Constitucional n. ${ }^{\circ} 53$, e regulamentado em 2007

1 No FUNDEF, o repasse de verbas era feito exclusivamente para o ensino fundamental público, excluindo EJA. $O$ veto à inclusão dessa modalidade de ensino foi feito pelo presidente Fernando Henrique Cardoso, na Emenda Constitucional 14/1996. 
pela Lei n. ${ }^{0} 11.494$ e pelo Decreto.$^{\circ}{ }^{6} 6.253$, o Fundo de Manutenção e Desenvolvimento da Educação Básica e de Valorização dos Profissionais da Educação (FUNDEB), com vigência estabelecida para o período 2007-2020 (BRASIL, 2006; MARTINS, 2009). Diferentemente do processo de tramitação do FUNDEF, o novo fundo foi amplamente debatido e mobilizou o parlamento e movimentos importantes da sociedade civil e das esferas subnacionais do poder público.

O novo fundo mantém as principais características do primeiro: redistribui recursos dentro de cada estado da federação para alunos matriculados na educação básica a partir de um valor mínimo definido nacionalmente, os estados que ficam abaixo desse valor recebem recursos da União. Já com relação ao gasto-aluno-mínimo, houve ampliação com previsão de diferenciação entre etapas e modalidades. A receita também sofreu mudanças, passando a receber um montante maior dos impostos já previstos pelo FUNDEF. Mas a grande melhoria do fundo está no fato de ele agora atender toda a educação básica (SOUZA; GOUVEIA; TAVARES, 2011).

Outra inovação importante do fundo foi a complementação da União. Ainda que tal previsão já existisse durante o FUNDEF, com o novo fundo há um nível mínimo de recursos a serem investidos pelo governo federal. De acordo com a Emenda n. 53/2006, a complementação deve corresponder a $10 \%$ (do fundo) da contribuição de estados e municípios quando estiver funcionando integralmente (BRASIL, 2006). Caso o valor por aluno não atinja o mínimo nacional, a União será requerida a complementá-lo. Acontece, contudo, que o cálculo do valor mínimo por aluno é feito mediante estimativas do FUNDEB, não é calculado com vinculação ao Custo-Aluno-Qualidade (CAQ), o qual será discutido posteriormente, ou seja, não é capaz de assegurar um orçamento que de fato financie um padrão mínimo de qualidade (MARTINS, 2009).

Mas, como já mencionado, o FUNDEB tem um prazo de vigência, que termina em 2020. Apesar de muitos pesquisadores considerarem a política de fundos como um caminho para a redistribuição dos recursos em educação, há uma grande preocupação em relação a esta política ainda permanecer nas Disposições Transitórias, não tendo sido incorporado na Constituição Federal, prejudicando, inclusive, a definição de planos de carreira do magistério (MARTINS, 2009; GOUVEIA; SOUZA, 2015). A proximidade do fim do FUNDEB também nos remete a pensar sobre alguns problemas que os fundos não deram conta de sanar, como a desigualdade do padrão da oferta dos serviços educacionais a todos os cidadãos, pois, de acordo com Abrucio (2010, p. 64):

Eles [o FUNDEF e o FUNDEB] conseguiram dar mais recursos aos governos que se responsabilizam pela política, mas mexeram pouco com as desigualdades regionais que marcam a federação brasileira. Para tanto, seria necessário que a União não só complementasse o dinheiro que falta para chegar à meta básica, mas que também fizesse política redistributiva. Caso contrário, a equalização se dá num patamar mínimo, e as redes dos estados mais ricos tendem a ter uma diferença substancial de condições em relação aos demais.

\section{O Debate sobre Custo e Gasto Aluno no Brasil}

O debate sobre a melhoria da qualidade da educação e sobre os recursos destinados a esse fim não são novos no Brasil. De acordo com Martins (2009), desde 1882 há discussão sobre a necessidade de um fundo escolar por província para financiar o ensino obrigatório. 
Porém, a discussão sobre a necessidade de estabelecer um custo por aluno foi aferida por Anísio Teixeira, em 1962, quando menciona no Conselho Federal de Educação "que deveria ser avaliado o custo por aluno da educação" (MARTINS, 2009, p. 101).

Em pesquisa encomendada pelo Instituto Nacional de Pesquisas em Educação Anísio Teixeira (INEP), Verhine (2006) afirma que estudos mais detalhados acerca dos custos educacionais vigoraram no Brasil em meados da década de 1970, por pesquisadores da área da economia.

Nos anos 1980, Vitor Paro (1981) fez um estudo precursor dos custos educacionais da cidade de São Paulo, Brasil, no qual traça bases para o cálculo de custo aluno-ano para estudos posteriores (VERHINE, 2006).

O autor discriminava os custos em Custos de Capital (prédios, equipamentos), Custos Correntes, Custos com Pessoal (docente em exercício, em função técnica ou administrativa), Custos com Consumo e Custos Sociais (alimentação e assistência odontológica) (PARO, 1981). O autor concluiu, entre outras coisas, que escolas menores de $2^{\circ}$ grau (hoje denominadas de ensino médio) e que atendiam classe social elevada, apresentavam custos maiores. Já as escolas maiores, que recebiam alunos do $1^{\circ} \mathrm{grau}$ (ensino fundamental) das classes sociais baixas, mostravam custos menores (PARO, 1981), evidenciando, assim, claras indicações de que o financiamento da educação contém relações diretas com as condições de distribuição de renda no Brasil.

Assim como Paro (1981), outros pesquisadores (VERHINE, 2006, PINTO, 2007; CAMARGO et al., 2006) também se debruçaram a explicitar o custo de um aluno por ano atendendo as determinações legais de garantia de um padrão mínimo de qualidade, que fora citado pela primeira vez no artigo 206 da Constituição de 1988: "O ensino será ministrado com base nos seguintes princípios: I - igualdade de condições para o acesso e permanência na escola [...]; V - Garantia de padrão de qualidade" (BRASIL, 1988).

A CF de 88, ao tratar dos "sistemas de ensino" vinculados à União, aos estados, ao Distrito Federal e aos municípios, estabelece que:

1. Os entes federados, apesar de constituírem entes autônomos, organizarão em regime de colaboração seus sistemas de ensino;

2. Caberá à União 'organizar o sistema federal de ensino e dos territórios e financiar as instituições de ensino públicas federais' (BRASIL. CF, art. 211, § $1^{\circ}$ );

3. Além das funções estabelecidas no item anterior, a União 'exercerá, em matéria educacional, função redistributiva e supletiva, de forma a garantir equalização de oportunidades educacionais e padrão mínimo de qualidade do ensino mediante assistência técnica e financeira aos Estados, ao Distrito Federal e aos Municípios'

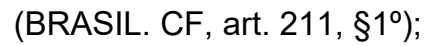

4. Os Municípios 'atuarão prioritariamente no ensino fundamental e na educação infantil' (BRASIL. CF, art. 211, § $1^{\circ}$ );

5. Os Estados e o DF 'atuarão prioritariamente no ensino fundamental e médio' (BRASIL. CF, art. $211, \S 1^{\circ}$;

6. Na organização de seus 'sistemas de ensino' os entes federados 'definirão formas de colaboração de modo a assegurar a universalização do ensino obrigatório' (BRASIL. CF, art. $211, \S 4^{\circ}$ ) (AMARAL et al., 2016, p. 15, grifos meus).

A Lei de Diretrizes e Bases Educação Nacional (LDB), em seu artigo 74 (BRASIL, 1996a), também menciona a questão da qualidade: "Cabe à União calcular, ao final de cada 
ano o custo mínimo por aluno capaz de assegurar ensino de qualidade". Já o artigo 75 define o papel da União em suplementar e redistribuir os recursos vinculados com a educação e garantir um padrão mínimo de qualidade.

Ademais, o Plano Nacional de Educação (PNE) também faz referência a essa temática quando cita a adequação da aprendizagem a um padrão mínimo de qualidade, definida pela LDB como a "[...] a variedade e quantidade mínimas, por aluno, de insumos indispensáveis ao desenvolvimento do processo de aprendizagem" (BRASIL, 1996a, art. 4a). Outra questão importante é que, o último PNE (2014-2024) toma como referência o conceito custo-alunoqualidade (CAQ) (PINTO, 2007), entregando a responsabilidade de ajuste financeiro ao padrão desejado pelos sistemas de ensino e dando à União função supletiva e de complementação dos recursos.

(Estratégia 20.6) No prazo de 2 (dois) anos da vigência deste PNE, será implantado o Custo Aluno-Qualidade inicial - CAQi, referenciado no conjunto de padrões mínimos estabelecidos na legislação educacional e cujo financiamento será calculado com base nos respectivos insumos indispensáveis ao processo de ensino-aprendizagem e será progressivamente reajustado até a implementação plena do Custo Aluno Qualidade CAQ;

(Estratégia 20.7) Implementar o Custo Aluno Qualidade - CAQ como parâmetro para o financiamento da educação de todas as etapas e modalidades da educação básica, a partir do cálculo e do acompanhamento regular dos indicadores de gastos educacionais com investimentos em qualificação e remuneração do pessoal docente e dos demais profissionais da educação pública, em aquisição, manutenção, construção e conservação de instalações e equipamentos necessários ao ensino e em aquisição de material didático-escolar, alimentação e transporte escolar (BRASIL, 2014).

A Campanha Nacional pelo Direito à Educação estabeleceu, em 2006, após muitos debates desde a década de 1990, o Custo-Aluno-Qualidade, que visa "[...] contribuir para o aumento do financiamento educacional visando a implementação de um conjunto articulado, duradouro e coerente de políticas que garantam uma educação pública de qualidade" (CARREIRA; PINTO, 2007, p. 39).

Em virtude do caráter polissêmico e dinâmico do conceito qualidade (OLIVEIRA; ARAUJO, 2005), elaborou-se, então, o CAQi, visando estabelecer padrões mínimos de qualidade que pudessem ser observados em todas as escolas das diferentes regiões do País. O CAQi pretende garantir a implantação do piso salarial para os professores, a melhoria da infraestrutura das escolas e a garantia de um número de alunos por sala de aula, visto que a qualidade educacional é diretamente impactada pelo tamanho das escolas, pela jornada dos alunos, pela relação de alunos por turma (ou por professor) e pelos salários dos profissionais da educação (CARREIRA; PINTO, 2007). Em síntese:

[...] O CAQi é o padrão mínimo de qualidade, por isso ele recebe o 'i' de inicial. Conforme a Lei $n^{\circ} 13.005 / 2014$, que estabelece o Plano Nacional de Educação, ele deve ser implementado até 2016. Já o CAQ avança em relação ao padrão mínimo, pois considera o caráter dinâmico do conceito de custo por aluno e também a capacidade econômica do Brasil, posicionado como uma das maiores economias do mundo. Assim, o CAQ é o padrão de qualidade que se aproxima dos padrões de oferta dos países mais desenvolvidos em termos educacionais (CARA et al., 2018, p. 19). 
Há, portanto, um desafio em se estabelecer um critério, uma metodologia para o cálculo do Custo-Aluno-Qualidade no sentido de promover amplo acordo nacional e compromisso de gestão em torno de tal conceito:

As discussões em curso acontecem, pela complexidade, subjetividade e polissemia presente no termo 'qualidade', bem como em função de desigualdade e assimetrias entre entes federativos, em um clima de disputa de concepções educativas, de pactuação interfederativa em foro legítimo e de tensão sobre os parâmetros e indicadores que serão utilizados (AMARAL et al., 2016, p. 23).

É válido ressaltar que existe um projeto em andamento, denominado como SIMCAQ2, que permitirá que o usuário calcule o custo da oferta da educação básica em condições de qualidade em cada município, estado ou em nível nacional para um período de até 10 anos.

\section{O Gasto Aluno-Ano no Estado do Paraná em 2017: breve análise}

O estado do Paraná é considerado um dos estados mais desenvolvidos do Brasil, apesar de seus 399 municípios apresentarem realidades socioeconômicas heterogêneas. Alguns desses municípios possuem maior expressão econômica, com altos índices em indicadores sociais, enquanto que, a outra parte, menos abastada, nem mesmo possui indicadores sociais satisfatórios. Como exemplo disso, pode-se observar a discrepância nos valores do $\mathrm{IDHM}^{3}$ entre as três cidades com o índice mais alto, Curitiba $(0,823)$, Maringá $(0,808)$ e Quatro Pontes $(0,796)$, em relação às três cidades com o índice mais baixo, Doutor Ulysses (0,546), Cerro Azul $(0,573)$ e Laranjal $(0,585)$, conforme dados do PNUD (2013).

Tal heterogeneidade retrata as desigualdades na condição de vida da população, representando a divergência na capacidade de geração de excedente econômico pelos municípios.

Todos os municípios do Paraná estão submetidos a um regime de colaboração no âmbito da educação, desde o início da década de 1990. Tal regime resultou em uma divisão da oferta de vagas no ensino fundamental entre as redes municipais e estadual, o município é responsável pelos anos iniciais e, o estado, pelos anos finais.

O cenário da última década evidencia a tendência no crescimento das redes municipais, por conta da reforma do Estado e descentralização do ensino, desde a CF de 1988 que "[...] possibilitou aos municípios criarem seus próprios sistemas de ensino, atribuindo aos mesmos autonomia relativa na formulação de políticas educacionais, em específico para a educação infantil e ensino fundamental I, uma vez que, até então, a esfera municipal detinha, apenas, sistema administrativo" (SOUZA; FARIA, 2004, p. 930).

Em 2017, a rede municipal apresentou $6,98 \%$ a mais no valor total das matrículas do que a rede estadual, como expresso na Tabela 1. Quanto ao ensino fundamental, há certo equilíbrio entre as matrículas por dependência administrativa nessa etapa da educação básica (o município apresenta 112.255 matrículas a mais que o estado). Já a creche e pré-escola

2 Disponível em: <http://www.custoalunoqualidade.org.br/simulador-basico-do-caqi>.

3 IDHM - compreende indicadores de três dimensões do desenvolvimento humano: longevidade, educação e renda. O índice varia de 0 a 1 . Quanto mais próximo de 1, maior o desenvolvimento humano, sendo considerado de 0 a 0,499 - muito baixo; de 0,500 a 0,599 - baixo; de 0,600 a 0,699 - médio; de 0,700 a 0,799 - alto e de 0,800 para cima - muito alto (PNUD, 2013). 
possuem as matrículas essencialmente no município, enquanto o ensino médio e ensino profissional estão com matrículas apenas no estado, como estipulado em lei.

Tabela 1 - Matrículas do Paraná no Ensino Regular segundo a Modalidade de Ensino e a Dependência Administrativa - 2017

\begin{tabular}{|r|r|r|r|r|r|}
\hline $\begin{array}{l}\text { MODALIDADE DE } \\
\text { ENSINO }\end{array}$ & \multicolumn{1}{|l|}{ IEDERAL } & ESTADUAL & \multicolumn{1}{l|}{ MUNICIPAL } & PARTICULAR & TOTAL \\
\hline Educação Infantil & 125 & 939 & 359.143 & 103.031 & 463.238 \\
\hline Creche & 125 & 125 & 152.357 & 49.348 & 201.955 \\
\hline Pré-escola & & 814 & 206.786 & 53.683 & 261.283 \\
\hline $\begin{array}{l}\text { Ensino Fundamental } \\
(1)\end{array}$ & 465 & 555.944 & 668.199 & 198.945 & 1.423 .553 \\
\hline Ensino Médio (2) & 7.414 & 374.306 & & 58.045 & 439.765 \\
\hline Educação profissional & 10.571 & 29.100 & & 39.230 & 78.901 \\
\hline TOTAL & 18.575 & 960.289 & 1.027 .342 & 399.251 & 2.868 .295 \\
\hline
\end{tabular}

Fonte: MEC/INEP apud IPARDES (2017).

(1) Inclui matrículas do ensino de 8 e 9 anos.

(2) Inclui as matrículas do ensino médio propedêutico, do ensino integrado à educação profissional e do ensino normal e/ou magistério.

Com o objetivo de calcular o valor do gasto aluno-ano da educação básica dos municípios do estado do Paraná, no ano de 2017, foram coletados dados financeiros disponíveis na página na internet da Secretaria do Tesouro Nacional (STN) do arquivo Finanças do Brasil (FINBRA) e também dados do Sistema de Informações sobre Orçamentos Públicos em Educação (SIOPE). Além disso, também foram coletados os dados de matrícula organizados nos censos escolares, estes disponíveis na página na internet do Instituto Nacional de Estudos e Pesquisas Educacionais Anísio Teixeira (INEP) do Ministério da Educação. Com isso, foi feita a seguinte divisão:

$$
\text { Gasto por aluno }=\frac{\text { Despesas liquidadas do município com educação }}{\mathrm{N}^{\circ} \text { de matrículas municipais }}
$$

É de suma importância ressaltar que, até o presente momento da escrita do artigo (julho de 2018), o FINBRA só continha informações financeiras de apenas 344 municípios, ou seja, a análise dos dados foi realizada com uma amostra de aproximadamente $85 \%$ dos casos.

Também é importante ressaltar que, o valor do gasto por aluno, ora estimado, é aproximado, pois está tomando o total de investimento em educação e o total de matrículas na rede municipal, sem considerar as diferenças entre níveis e modalidades ou outras características da rede municipal de ensino, como a existência de convênios para o atendimento de educação infantil e educação especial.

É válido também elucidar que o estado do Paraná, mesmo sob a lógica da distribuição de recursos desde 1988, não obteve recursos complementares da União via FUNDEB em nenhum ano. Em tese, pode-se dizer que o estado possui arrecadação tributária suficiente para financiar sua rede de ensino. 
A partir dos dados disponíveis, foi possível realizar uma análise estatística com o intuito de aferir os valores máximo e mínimo dos gastos por aluno, bem como a média de gastos, a mediana ${ }^{4}$, o desvio padrão ${ }^{5}$ e os quartis, conforme tabela abaixo:

Tabela 2 - Informações gerais sobre o gasto-aluno anual de alguns municípios do Paraná, em 2017

\begin{tabular}{|c|c|c|}
\hline \multirow{2}{*}{ Valores } & Válido & 344 \\
\hline & Ausente & 0 \\
\hline \multicolumn{2}{|l|}{ Média } & $\mathrm{R} \$ 7.984,85$ \\
\hline \multicolumn{2}{|l|}{ Mediana } & $\mathrm{R} \$ 7.580,51$ \\
\hline \multicolumn{2}{|l|}{ Desvio padrão } & $\mathrm{R} \$ 1.729,41$ \\
\hline \multicolumn{2}{|l|}{ Mínimo } & $\mathrm{R} \$ 4.779,62$ \\
\hline \multicolumn{2}{|l|}{ Máximo } & $\mathrm{R} \$ 15.343,73$ \\
\hline \multirow{3}{*}{ Percentis } & 25 & $6.797,35$ \\
\hline & 50 & $7.580,51$ \\
\hline & 75 & $8.964,07$ \\
\hline
\end{tabular}

Fonte: STN (FINBRA), Censo Escolar/INEP (2017).

A média de gasto anual por aluno ficou em $R \$ 7.984,85$, mas o valor da mediana foi um pouco mais baixo. Isso significa que, $50 \%$ dos 344 municípios, gastaram por aluno, no ano de 2017 , até o valor de $\mathrm{R} \$ 7.580,51$, enquanto os outros $50 \%$ gastaram acima desse valor. Sendo que, o primeiro quartil dos municípios teve um gasto mais baixo que $\mathrm{R} \$ 6.797,35$, enquanto o terceiro quartil gastou acima de $\mathrm{R} \$ 8.964,07$.

No entanto, o que mais salta aos olhos nessa tabela é a diferença entre o valor máximo, que é o valor mais alto encontrado no estado, e o valor mínimo, que é o menor valor encontrado. Verificou-se, no mesmo estado, um município com o gasto anual por aluno de $\mathrm{R} \$ 15.343,73$, enquanto que, outro, gastou apenas $\mathrm{R} \$ 4.779,62$, ou seja, em um mesmo estado da Federação, um município investiu aproximadamente três vezes mais do que outro.

Esses dados evidenciam a disparidade de condições dos municípios para investimento em educação. Essa discrepância na alocação de recursos financeiros pode colocar em xeque o que deveria ser cumprido pela lei, como já tratado anteriormente, "[...] variedade e quantidade mínimas, por aluno, de insumos indispensáveis ao desenvolvimento do processo de aprendizagem" (BRASIL, 1996a, art. 4ª), acarretando, assim, em graves disparidades de oportunidades educacionais.

Só a absurda tolerância à desigualdade, uma marca que influencia e configura as políticas públicas no país, pode explicar a enorme resistência à ideia intuitiva e simples de que todos os estudantes deveriam dispor dos mesmos recursos básicos necessários à sua escolarização, independentemente de sua naturalidade ou local de residência (CARA et al., 2018, p. 61).

4 Mediana é o valor que centra a distribuição, ou seja, que a divide em duas partes de frequências iguais (OLIVEIRA, 1999, p. 14).

5 O protótipo das medidas de dispersão em virtude de suas propriedades matemáticas e de seu uso na teoria da amostragem (OLIVEIRA, 1999, p. 16). Quando o desvio-padrão for grande, os valores da variável estarão muito longe de sua média e, se for igual a zero, então todos os valores são iguais. 
O Gasto Aluno-Ano no Estado do Paraná em 2017

\section{Os Valores Máximo e Mínimo}

\section{a) Itaipulândia}

O município tratado anteriormente como valor máximo, na Tabela 2, que teve um gastoaluno de $\mathrm{R} \$ 15.343,73$, no ano de 2017 , é o município de Itaipulândia, localizado na região oeste do estado do Paraná, com uma população de 10.413 habitantes (IBGE, 2010) e o IDHM de 0,738 . É um município de porte pequeno, com um total de 2.577 matrículas na educação básica, sendo 1.453 matrículas municipais distribuídas em 10 escolas e com um quadro de 134 docentes.

A economia do município é essencialmente agrícola, porém, com a construção da Usina Hidrelétrica de Itaipu, no final da década de 1970, metade de suas terras agricultáveis foram inundadas pelo lago da represa. Como forma de atenuar o impacto ambiental, a Itaipu Binacional compensa o município pagando royalties, o que faz com que o município tenha uma das maiores rendas per capita da região, estimada em $R \$ 29.382,91$, segundo dados do IBGE, 2015.

Os royalties são o valor pago ao detentor de uma marca, patente, processo de produção, produto ou obra original pelos direitos de sua exploração comercial. Os detentores recebem percentagem das vendas dos produtos produzidos com o consumo de suas marcas, processos, etc., ou dos lucros obtidos com estas operações (SANDONI, 1989, p. 386 apud EBERHARDT, 2002, p. 25).

O valor do repasse aos 16 municípios paranaenses beneficiados pelos royalties da Itaipu Binacional varia mensalmente conforme a geração de energia mensal comercializada. No ano de 2017, a arrecadação líquida recebida desse valor extra no município de Itaipulândia foi de $\mathrm{R} \$ 61.458 .460,33^{6}$ segundo dados retirados no site da internet da prefeitura ${ }^{7}$ do referido município. Valor bem expressivo, tendo em vista o tamanho do município e a sua receita própria realizada.

Os dados apresentados na Tabela abaixo mostram, na primeira coluna, o valor arrecadado pelo município por meio dos impostos de natureza própria (IPTU, ITBI e ISS). Já a coluna dois revela a receita de transferências constitucionais e legais, realizada pela União e estado por meio da distribuição do valor arrecadado com os seguintes impostos: FPM, ITR, IPVA, IOF e ICMS.

É possível notar que a União e o Estado transferem vinte vezes a mais o valor adquirido pelo próprio município, um montante de $\mathrm{R} \$ 23.759 .968,5$. Com relação às receitas destinadas e recebidas do FUNDEB, o município consegue ficar com um saldo líquido positivo no valor de $\mathrm{R} \$ 806.518,05$.

\footnotetext{
6 Esse valor foi retirado do site da Prefeitura Municipal de Itaipulândia, o qual conta com uma página do "PRONIM Transparência Brasil", onde é possível angariar vários dados das receitas, despesas e transferências da administração pública do município: <http://170.82.11.239:8070/pronimtb/>.

7 Disponível em: <http://www.itaipulandia.pr.gov.br/>
} 
O Gasto Aluno-Ano no Estado do Paraná em 2017

Tabela 3 - Receitas próprias e de transferências do município de Itaipulândia, 2017

\begin{tabular}{|c|c|c|c|c|c|}
\hline ANO & $\begin{array}{c}\text { Receita } \\
\text { própria } \\
\text { realizada }\end{array}$ & $\begin{array}{c}\text { Receita de } \\
\text { transferências } \\
\text { constitucionais e } \\
\text { legais }\end{array}$ & $\begin{array}{c}\text { Receitas } \\
\text { destinadas ao } \\
\text { FUNDEB }\end{array}$ & $\begin{array}{c}\text { Receitas } \\
\text { recebidas do } \\
\text { FUNDEB }\end{array}$ & $\begin{array}{c}\text { Resultado } \\
\text { líquido das } \\
\text { transferências } \\
\text { do FUNDEB }\end{array}$ \\
\hline 2017 & $3.794 .630,83$ & $23.759 .968,51$ & $4.560 .572,35$ & $5.414 .226,65$ & $806.518,65$ \\
\hline
\end{tabular}

Fonte: Elaborado pela autora com base em SIOPE (2017).

Outro fato relevante de se expor sobre o orçamento do município é que, o valor arrecadado através do FUNDEB, no ano de 2017, foi gasto integralmente com o pagamento do magistério, conforme dados do SIOPE:

Tabela 4 - Indicadores do FUNDEB - Itaipulândia, 2017

\begin{tabular}{|l|c|}
\hline \multicolumn{1}{|c|}{ Total das despesas do FUNDEB para fins de limite } & Valor \\
\hline Mínimo de 60\% do FUNDEB na remuneração do Magistério & $99,89 \%$ \\
\hline Máximo de 40\% em Despesas com MDE, que não Remuneração do Magistério & 0 \\
\hline Máximo de 5\% não Aplicado no Exercício & $0,11 \%$ \\
\hline
\end{tabular}

Fonte: Elaborado pela autora com base em SIOPE (2017).

Provavelmente isso se explique por conta do Artigo $8^{\circ}$ da Lei $7.990 / 1989$, que proíbe a utilização de royalties para pagamento de pessoal e dívidas do município.

\begin{abstract}
Art. $8^{\circ} \mathrm{O}$ pagamento das compensações financeiras previstas nesta Lei, inclusive o da indenização pela exploração do petróleo, do xisto betuminoso e do gás natural será efetuado, mensalmente, diretamente aos Estados, ao Distrito Federal, aos Municípios e aos órgãos da Administração Direta da União, até o último dia útil do segundo mês subsequente ao do fato gerador, devidamente corrigido pela variação do Bônus do Tesouro Nacional (BTN), ou outro parâmetro de correção monetária que venha a substituí-lo, vedada a aplicação dos recursos em pagamento de dívida e no quadro permanente de pessoal.
\end{abstract}

Isso indica que o município também utilizou outras fontes de recurso para custear as demais despesas do orçamento com educação, advindas em grande parte pelas receitas de transferências do FNDE, como consta na Tabela 6, e provavelmente também com uma parte dos recursos oriundos dos royalties da Itaipu Binacional, porém, não foi possível trazer esse dado através das análises do SIOPE (2017).

Tabela 5 - Receitas Adicionais para Financiamento do Ensino - Itaipulândia, 2017

\begin{tabular}{|l|lr|}
\hline Receita & \multicolumn{2}{|c|}{ Valor } \\
\hline $\begin{array}{l}\text { Receita da aplicação financeira de outros recursos de } \\
\text { impostos vinculados ao ensino }\end{array}$ & $\mathrm{R} \$$ & $16.745,24$ \\
\hline Receita de transferências do FNDE & $\mathrm{R} \$$ & $731.458,77$ \\
\hline Outras receitas para financiamento do ensino & $\mathrm{R} \$$ & $15.000,00$ \\
\hline Total & $\mathrm{R} \$$ & $763.204,01$ \\
\hline
\end{tabular}

Fonte: Elaborado pela autora com base em SIOPE (2017).

Na tabela abaixo é possível observar que o valor gasto com ações típicas de Manutenção e Desenvolvimento do Ensino na educação infantil não foi custeado com recursos do FUNDEB, 
enquanto que, no ensino fundamental, o fundo custeia quase toda a despesa, grande parte delas o custeio da folha de pagamento do magistério, como já tratado acima.

Dos recursos aplicados em MDE, pelo menos $60 \%$ estão subvinculados à educação básica (Emenda Constitucional 53/2006), conforme a Tabela 6 demonstra:

Tabela 6 - Despesas com ações típicas de MDE - Itaipulândia, 2017

\begin{tabular}{|l|c|}
\hline 1. Educação Infantil & $2.703 .472,16$ \\
\hline Despesas custeadas com Recursos do FUNDEB & 0 \\
\hline Despesas custeadas com outros recursos de impostos & $2.703 .472,16$ \\
\hline 2. Ensino Fundamental & $6.896 .883,93$ \\
\hline Despesas custeadas com Recursos do FUNDEB & $5.597 .714,79$ \\
\hline Despesas custeadas com outros recursos de impostos & $1.299 .169,14$ \\
\hline $\begin{array}{l}\text { Percentual de aplicação em MDE sobre a receita } \\
\text { líquida de impostos }\end{array}$ & $34,88 \%$ \\
\hline Total das despesas com ações típicas de MDE & $9.600 .356,09$ \\
\hline Total Geral das despesas com educação & $\mathbf{2 0 . 5 9 1 . 0 6 9 , 5 7}$ \\
\hline
\end{tabular}

Fonte: Elaborado pela autora com base em SIOPE (2017).

Outro aspecto incomum, com relação ao orçamento desse município, é o financiamento da educação superior.

Como previsto no Art. 11, V, LDB 9394/96, os municípios incumbir-se-ão de:

[...] V - Oferecer a educação infantil em creches e pré-escolas e, com prioridade, o ensino fundamental, permitida a atuação em outros níveis de ensino somente quando estiverem atendidas plenamente as necessidades de sua área de competência $e$ com recursos acima dos percentuais mínimos vinculados pela Constituição Federal à manutenção e desenvolvimento do ensino (BRASIL, 1996).

Devido à pequena população e ao grande valor recebido pelos royalties da Itaipu Binacional, Itaipulândia conseguiu possivelmente atender toda a sua demanda educacional tanto na etapa da educação infantil quanto no ensino fundamental.

Segundo dados do IBGE (2010), a taxa de escolarização de crianças de 6 a 14 anos de idade no município de Itaipulândia é de 99,2\%. Já com relação à etapa da educação infantil, os dados disponíveis permitem deduzir que a demanda foi atendida, uma vez que, em 2010, o município possuía 610 crianças na faixa etária do 0 a 5 anos e, em 2018, segundo o censo escolar, a taxa de matrícula na educação infantil era de 772 estudantes. É evidente que a análise fica prejudicada devido aos limites metodológicos da coleta da informação por município no censo populacional ser apenas de dez em dez anos.

Ademais, como já trazido anteriormente, também conseguiu alocar recursos acima do percentual mínimo em MDE (34,88\%). Em função disso, o município possui uma lei que, desde 2003, instituiu o Programa de Subsídio Educacional, o qual prevê um suporte financeiro ao aluno que estiver cursando o ensino superior em outra cidade ou estado, visto que o próprio município não atende a essa etapa de ensino:

Art. $1^{\circ}$ Fica instituído o Programa Municipal de Subsídio Educacional, destinado a dar suporte financeiro ao estudante do Município de Itaipulândia, durante o período em que estiver cursando o $3^{\circ}$ Grau ou Curso de Pós-graduação, consistindo o mesmo em 
reembolso ao aluno do valor de $50 \%$ da mensalidade, até o limite de desembolso pelo município de valor equivalente até $125 \%$ de um salário mínimo vigente no Paraná, por mês, para instituição privada e, quando aluno de instituição pública, o fomento representado pela ajuda de custo em valor equivalente de até $75 \%$ de um salário mínimo vigente no Paraná, por mês (ITAIPULÂNDIA, 2003).

O valor gasto com essa etapa de ensino, no ano de 2017 , foi de $R \$ 2.942 .465,83$, valor significativo dentre o montante total investido em educação. Esse dado acabou modificando o resultado da pesquisa, uma vez que a análise do gasto-aluno seria feita apenas com as matrículas da educação básica.

Ao retirar esse montante aplicado ao ensino superior, o gasto aluno-ano efetivo na educação básica decai para $\mathrm{R} \$ 13.197,67$. Ou seja, o município deixaria de ocupar o valor máximo na análise do gasto aluno-ano no estado do Paraná.

Seria interessante um estudo posterior que analisasse somente o município em questão, a fim de verificar as inconsistências trazidas nesse primeiro estudo, bem como outras questões levantadas, como o impacto dos royalties na educação do município, a eficiência dos gastos, entre outros.

\section{b) Colombo}

O município do Paraná com o menor valor no gasto aluno ( $R \$ 4.779,62)$, em 2017 , foi Colombo, que faz parte da mesorregião metropolitana de Curitiba. Possui uma população de 203.203 habitantes e IDHM de 0,733 (IBGE, 2010). Sua economia se baseia na indústria extrativa de minério e na agricultura, tendo um PIB per capita no valor de $R \$ 18.896,33$, segundo dados do IBGE (2010).

Com relação aos dados educacionais, o município apresenta o total de 53.471 matrículas, sendo 26.068 de responsabilidade municipal, distribuídas em 87 escolas, e conta com um quadro de 1.267 docentes.

Em relação aos dados orçamentários obtidos por meio do Sistema de Informações sobre Orçamentos Públicos em Educação (SIOPE), observa-se que o resultado líquido das transferências do FUNDEB no município, em 2017, foi positivo.

É interessante também analisar que o valor recebido pelo fundo quase se iguala ao valor total da receita própria gerada pelo município. Isso mostra o quanto a política de fundos é importante para garantir maior redistribuição de investimento em educação, pois, caso não recebesse esse valor, provavelmente não conseguiria atender toda a sua demanda educacional (Tabela 8).

Tabela 8 - Receitas Próprias e de Transferências do Município de Colombo, 2017

\begin{tabular}{|c|c|c|c|c|c|}
\hline ANO & $\begin{array}{c}\text { Receita } \\
\text { própria } \\
\text { realizada }\end{array}$ & $\begin{array}{c}\text { Receita de } \\
\text { transferências } \\
\text { constitucionais e } \\
\text { legais }\end{array}$ & $\begin{array}{c}\text { Receitas } \\
\text { destinadas ao } \\
\text { FUNDEB }\end{array}$ & $\begin{array}{c}\text { Receitas } \\
\text { recebidas do } \\
\text { FUNDEB }\end{array}$ & $\begin{array}{c}\text { Resultado } \\
\text { líquido das } \\
\text { transferências } \\
\text { do FUNDEB }\end{array}$ \\
\hline 2017 & $68.063 .687,13$ & $159.055 .566,83$ & $30.585 .608,46$ & $98.645 .226,97$ & $67.238 .842,02$ \\
\hline \multicolumn{5}{|c|}{ Fonte: Elaborado pela autora com base em SIOPE (2017). }
\end{tabular}

No que condiz aos indicadores do FUNDEB, nota-se que o município cumpriu com o previsto em lei, ou seja, teve um percentual acima de $60 \%$ na alocação de recursos para a remuneração do magistério (Tabela 9). 
Tabela 9 - Indicadores do FUNDEB - Colombo, 2017

\begin{tabular}{|l|r|}
\hline \multicolumn{1}{|c|}{ Total das despesas do FUNDEB para fins de limite } & \multicolumn{1}{|c|}{ Valor } \\
\hline Mínimo de 60\% do FUNDEB na remuneração do Magistério & $71,39 \%$ \\
\hline Máximo de 40\% em Despesas com MDE, que não Remuneração do Magistério & $27,55 \%$ \\
\hline Máximo de 5\% não Aplicado no Exercício & $0,11 \%$ \\
\hline
\end{tabular}

Fonte: Elaborado pela autora com base em SIOPE (2017).

Já, na Tabela 10, é possível observar as despesas com ações típicas de MDE entre as etapas de ensino da educação infantil e ensino fundamental. Diferente do município de Itaipulândia, Colombo faz uso do recurso do FUNDEB não só para o pagamento do magistério, mas também para as outras despesas que contemplam a Manutenção e Desenvolvimento do Ensino, conseguindo aplicar o percentual mínimo da exigência legal de 25\%.

Tabela 10 - Despesas Com Ações Típicas De MDE - Colombo, 2017

\begin{tabular}{|l|c|}
\hline 1. Educação Infantil & $36.215 .580,09$ \\
\hline Despesas custeadas com Recursos do FUNDEB & $27.652 .694,32$ \\
\hline $\begin{array}{l}\text { Despesas custeadas com outros recursos de } \\
\text { impostos }\end{array}$ & $8.562 .885,77$ \\
\hline 2. Ensino Fundamental & $81.351 .661,09$ \\
\hline Despesas custeadas com Recursos do FUNDEB & $65.092 .252,02$ \\
\hline $\begin{array}{l}\text { Despesas custeadas com outros recursos de } \\
\text { impostos }\end{array}$ & $16.259 .409,07$ \\
\hline $\begin{array}{l}\text { Percentual de aplicação em MDE sobre a receita } \\
\text { líquida de impostos }\end{array}$ & $25,59 \%$ \\
\hline Total das despesas com ações típicas de MDE & $117.567 .241,18$ \\
\hline Total Geral das despesas com educação & $\mathbf{1 2 4 . 5 9 5 . 1 2 9 , 0 2}$ \\
\hline
\end{tabular}

Fonte: Elaborado pela autora com base em SIOPE (2017).

Evidencia-se que o município consegue cumprir com o disposto em lei sobre o percentual mínimo de recursos que devem ser alocados para a educação. Porém, esses valores não são suficientes para a equiparação do valor gasto por aluno entre Colombo e os demais municípios analisados.

Como os dados anteriores evidenciaram, a média do gasto aluno no Paraná, em 2017, ficou em $\mathrm{R} \$ 7.984,85$. Logo, o município ainda precisa ter um aumento de $67,06 \%$ para alcançar o valor médio de gasto.

No entanto, Colombo possui baixa atividade econômica, arrecadação tributária limitada e inchaço populacional. Todos esses fatores influenciam diretamente nas limitações para o aumento do valor do gasto aluno no município.

A inserção metropolitana faz de Colombo uma cidade tipicamente dormitório, e parte integrante de uma totalidade metropolitana, e o que Ihe dá sentido é a função da contiguidade espacial com Curitiba, que por razões diversas, passou a concentrar uma grande quantidade de população de baixa renda, além disso, trata-se de um município não integrado ao processo de industrialização recente permanecendo com uma estrutura produtiva tradicional, voltada à extração e processamento do calcário (KATZINSKY, 2004, p. 7). 
Nesse sentido, ressalta-se que a vinculação da receita de impostos, mesmo sendo uma forma de assegurar recursos para a educação, tende a causar uma disparidade de investimentos, pois a arrecadação dos entes é muito desigual. A política de fundos foi estruturada com o intuito de promover uma redistribuição de recursos segundo o número de alunos matriculados, mas só a subvinculação feita pela política de fundos parece não corrigir as disparidades de investimento.

\section{Considerações Finais}

Finalmente, cabe observar simultaneamente os valores até aqui tratados dos dois municípios, que foram escolhidos por terem aparecido como valor máximo e mínimo no gasto aluno, em 2017, dentre a amostra dos 344 municípios do Paraná.

Tabela 11 - Características dos municípios de Itaipulândia e Colombo - Paraná, 2017

\begin{tabular}{|l|r|r|}
\hline \multicolumn{1}{|c|}{2017} & \multicolumn{2}{l|}{ ltaipulândia } \\
\hline População & 10.413 & 237.402 \\
\hline PIB per capita & $29.382,91$ & $18.896,33$ \\
\hline Royalties da Itaipu Binacional & $61.458 .460,33$ & Não recebe \\
\hline Matrículas municipais & 1.453 & 26.068 \\
\hline Gasto-aluno total & $15.343,73$ & $4.779,62$ \\
\hline $\begin{array}{l}\text { Gasto-aluno somente com educação } \\
\text { básica }\end{array}$ & $13.197,67$ & $4.779,62$ \\
\hline Receita própria & $3.794 .630,83$ & $68.063 .687,13$ \\
\hline $\begin{array}{l}\text { Receita de transferências constitucionais } \\
\text { e legais }\end{array}$ & $23.759 .968,51$ & $159.055 .566,83$ \\
\hline Receitas destinadas ao FUNDEB & $4.560 .572,35$ & $30.585 .608,46$ \\
\hline Receitas recebidas do FUNDEB & $5.414 .226,65$ & $98.645 .226,97$ \\
\hline Despesas liquidadas em educação & $22.118 .692,3$ & $124.595 .129,02$ \\
\hline $\begin{array}{l}\text { Resultado líquido das transferências do } \\
\text { FUNDEB }\end{array}$ & $806.518,65$ & $67.238 .842,02$ \\
\hline $\begin{array}{l}\text { Percentual de aplicação em MDE sobre a } \\
\text { receita líquida de impostos }\end{array}$ & $34,88 \%$ & $25,59 \%$ \\
\hline
\end{tabular}

Fonte: Elaborado pela autora com base em IBGE (2010), Censo Escolar (2017), SIOPE (2017), FINBRA (2017).

A partir da Tabela 11, é possível averiguar nitidamente o quanto os dois municípios são diferentes. Pode-se observar que Colombo possui uma população 20 vezes maior que Itaipulândia e, consequentemente, uma demanda educacional maior, no número de matrículas, escolas e docentes.

Contudo, devido à receita recebida de Royalties da Itaipu Binacional, o município de Itaipulândia possui uma das maiores rendas per capita do estado do Paraná e isso influencia em todos os demais aspectos. Por exemplo, a escolha em utilizar integralmente o recurso do FUNDEB para pagamento do magistério, o percentual de aplicação em MDE quase $10 \%$ a mais do que o mínimo legal e a criação do Programa de Subsídio Educacional para cidadãos itaipulandienses que queiram cursar graduação ou pós-graduação em outra cidade ou estado.

Ao mesmo tempo, o município de Colombo sofre com baixa atividade econômica, arrecadação tributária limitada e inchaço populacional. Mas, ainda assim, é notório que o município conseguiu, no ano de 2017 , cumprir com os valores mínimos dispostos em lei (60\% do FUNDEB para pagamento do magistério e $25 \%$ de aplicação em MDE). 
O presente artigo teve apenas a intenção de evidenciar e analisar a discrepância dos valores extremos do gasto aluno-ano em um mesmo estado e de abrir discussão sobre as disparidades educacionais marcadas por diferentes investimentos em educação.

Contudo, fazem-se necessários estudos mais aprofundados para afirmar se a diferença de investimento na educação entre os dois municípios acarreta diretamente na qualidade do ensino de ambos. Pois, como já bem discutido pela literatura, a alocação de recursos é parte importante para a garantia do direito à educação de qualidade.

O que se pôde evidenciar também é a problemática da submissão da política educacional à política econômica. No município que recebe outras fontes de recurso (royalties), houve investimento significativo em educação, enquanto no outro, que está à mercê de sua limitada arrecadação tributária, houve baixo investimento por aluno.

Por fim, é válido ressaltar que a vinculação da receita de impostos, mesmo sendo uma forma de assegurar recursos para a educação, acaba causando uma disparidade de investimentos, pois a arrecadação dos entes é muito desigual. A política de fundos foi estruturada com o intuito de promover uma redistribuição de recursos segundo o número de alunos matriculados, mas só a subvinculação feita pela política de fundos parece não corrigir as disparidades de investimento.

\section{Referências}

ABRÚCIO, Fernando Luiz. A dinâmica federativa da educação brasileira: diagnóstico e propostas de aperfeiçoamento. In: OLIVEIRA, Romualdo Portela de; SANTANA, Wagner (Org.). Educação e Federalismo no Brasil: combater as desigualdades, garantir a diversidade. Brasília, DF: UNESCO, 2010. p. 39-70.

ADRIÃO, Theresa. As relações entre o público e o privado na oferta educacional no Brasil. In: PINTO, José Marcelino; SOUZA, Silvana Aparecida de (Org.). Para onde vai o dinheiro? Caminhos de descaminhos do financiamento da educação. São Paulo: Xamã, 2014. p. 97-111.

AMARAL, Nelson Cardoso et al. Financiamento da Educação e o Custo Aluno-Qualidade (CAQ). Caderno Temático 9. Camaragibe: CCS Gráfica e Editora, 2016.

BRASIL. Constituição da República Federativa do Brasil. Diário Oficial da União, Brasília, 1988.

BRASIL. Lei n 9.394, de 20 de dezembro de 1996. Estabelece as diretrizes e bases da educação nacional. Diário Oficial da União, Brasília,1996a.

BRASIL. Lei $n^{\circ}$ 9.424, de 24 de dezembro de 1996. Dispõe sobre o Fundo de Manutenção e Desenvolvimento do Ensino Fundamental e de Valorização do Magistério, na forma prevista no art. $60, \S 7^{\circ}$, do Ato das Disposições Constitucionais Transitórias, e dá outras providências. Diário Oficial da União, Brasília,1996b.

BRASIL. Emenda constitucional $n^{\circ} 53$, de 19 de dezembro de 2006. Dá nova redação aos arts. $7^{\circ}$, 23, 30, 206, 208, 211 e 212 da Constituição Federal e ao art. 60 do Ato das Disposições Constitucionais Transitórias. Diário Oficial da União, Brasília, 2006.

BRASIL. Lei n. ${ }^{11.494}$, de 20 de junho de 2007. Regulamenta o Fundo de Manutenção e Desenvolvimento da Educação Básica e de Valorização dos Profissionais da Educação - Fundeb.

Diário Oficial da União, Brasília, 2007. 
O Gasto Aluno-Ano no Estado do Paraná em 2017

BRASIL. Lei n. ${ }^{\circ}$ 13.005, de 25 de junho de 2014. Aprova o Plano Nacional de Educação - PNE e dá outras providências. Diário Oficial da União, Brasília, 2014.

BRASIL. Portaria Interministerial n. ${ }^{\circ}$ 8, de 26 de dezembro de 2016. Estabelece os parâmetros operacionais para o Fundo de Manutenção e Desenvolvimento da Educação Básica e de Valorização dos Profissionais da Educação - FUNDEB, no exercício de 2017. Diário Oficial da União, Brasília, 2016.

CAMARGO, Rubens Barbosa de et al. Problematização da qualidade em pesquisa de custo aluno-ano em escolas de educação básica: relatório de pesquisa. Brasília: INEP/MEC, 2006.

CARA, Daniel et al. CAQI e CAQ no PNE: quanto custa a educação pública de qualidade no Brasil? São Paulo: Campanha Nacional pelo Direito à Educação, 2018.

CARREIRA, Denise; PINTO, José Marcelino R. Custo aluno-qualidade inicial: rumo à educação pública de qualidade no Brasil. Campanha Nacional pelo Direito à Educação, 2007.

EBERHARDT, Edílson. Os municípios lindeiros e a influência dos royalties. 2002. 37 f. Trabalho de Conclusão de Curso (Graduação em Geografia) - Universidade Estadual do Oeste do Paraná, Marechal Cândido Rondon, 2002.

FARENZENA, Nalú. A política de financiamento da Educação básica: rumos da legislação brasileira. Porto Alegre: UFRGS, 2006.

GOUVEIA, Andréa Barbosa; SILVA, Isabelle Fiorelli. O gasto aluno-ano no Paraná (Brasil) e a situação de financiamento da educação nas regiões metropolitanas do Estado. Perspectiva, v. 30, p. 305-321, 2012.

GOUVEIA, Andréa Barbosa; SOUZA, Ângelo Ricardo de. A política de fundos em perspectiva histórica: mudanças de concepção da política na transição Fundef e Fundeb. Em Aberto, Brasília, Instituto Nacional de Estudos e Pesquisas Educacionais Anísio Teixeira (INEP), v. 28, n. 93, p. 4565, jan.jjun. 2015.

IBGE. Instituto Brasileiro de Geografia e Estatística. Censo 2010. Rio de Janeiro, 2010.

IPARDES. Instituto Paranaense de Desenvolvimento Econômico e Social. Caderno Estatístico: Município de Itaipulândia. Julho 2018a. Disponível em: <http://www.ipardes.gov.br>. Acesso em: 14 jul. 2018.

IPARDES. Instituto Paranaense de Desenvolvimento Econômico e Social. Caderno Estatístico: Município de Colombo. Julho 2018b. Disponível em: http://www.ipardes.gov.br. Acesso em 12/07/2018.

ITAIPULÂNDIA. Lei Municipal n. 677 de 29 de setembro de 2003. Institui o Programa de Subsídio Educacional e dá outras providências. Diário Oficial, Câmara Municipal da Itaipulândia, Itaipulândia, 2003.

KATZINSKY, Luciane. A análise da relação Colombo e Curitiba à luz da teoria dos dois circuitos da economia urbana. 2004. Dissertação (Mestrado em Geografia) - Universidade Federal do Paraná, Curitiba, 2004.

MARTINS, Paulo de Sena. O financiamento da Educação Básica por meio de fundos contábeis: estratégia política para a equidade, a autonomia e o regime de colaboração entre os 
O Gasto Aluno-Ano no Estado do Paraná em 2017

entes federados. 2009. 337 f. Tese (Doutorado em Educação) - Universidade de Brasília, Brasília, 2009.

OLIVEIRA, Cleiton et al. Municipalização do ensino no Brasil. Belo Horizonte: Autêntica, 1999.

OLIVEIRA, Estevam Martins de. Estatística e probabilidade: exercícios resolvidos e propostos. 2. ed. São Paulo: Atlas, 1999.

OLIVEIRA, Romualdo Portela de; ARAUJO, Gilda Cardoso de. Qualidade do ensino: uma nova dimensão da luta pelo direito à educação. Revista Brasileira de Educação, Rio de Janeiro, n. 28, p. 5-24, 2005. Disponível em: <http://www.scielo.br/pdf/rbedu/n28/a02n28>. Acesso em: 02 jul. 2018.

PARO, Vitor $\mathrm{H}$. Estudo comparativo sobre custo-aluno nos diversos graus e modalidades rumo à educação pública de qualidade no Brasil. São Paulo: Global; Campanha Nacional pelo Direito à Educação, 1981.

PINTO, José Marcelino de Rezende. A política recente de fundos para o financiamento da educação e seus efeitos no pacto federativo. Educação \& Sociedade, Campinas, v. 28, n. 100, pp. 877- 897, 2007.

PNUD. Programa das Nações Unidas para o Desenvolvimento. Atlas do Desenvolvimento Humano dos Municípios. 2013. Disponível em: <http://www.pnud.org.br/>. Acessado em: 02 jul. 2018.

SOUZA, Ângelo Ricardo de; GOUVEIA, Andréa Barbosa; TAVARES, Taís (Org.) Políticas Educacionais: conceitos e debates. Curitiba: Editora Appris, 2011.

SOUZA, Donaldo Bello de; FARIA, Lia Ciomar. Reforma do estado, descentralização e municipalização do ensino no Brasil: a gestão política dos sistemas públicos de ensino pós-LDB 9.394/96. Ensaio, Rio de Janeiro, v. 12, n. 45, p. 925-944, 2004.

VERHINE, Robert. Custo-Aluno-Qualidade em Escolas de Educação Básica. $2^{\mathrm{a}}$ Etapa. Relatório Nacional da Pesquisa. In: CAMARGO, Rubens Barbosa de et al. Problematização da qualidade em pesquisa de custo aluno-ano em escolas de educação básica: relatório de pesquisa. Brasília: INEP/MEC, 2006.

Isabella de Meira Araujo é mestranda no Programa de Pós-Graduação em Educação (PPGE), linha: Políticas Educacionais na Universidade Federal do Paraná (UFPR). Possui graduação em Pedagogia pela Universidade Federal do Paraná (2017). Atualmente é professora do Ensino Fundamental, anos iniciais, na Prefeitura Municipal de Curitiba.

ORCID: http://orcid.org/0000-0002-3193-9403

E-mail: isabellaaraujo0704@gmail.com 


\section{Editores do volume 9}

José Marcelino de Rezende Pinto - Universidade de São Paulo, São Paulo/SP, Brasil

Nalú Farenzena - Universidade Federal do Rio Grande do Sul, Porto Alegre/RS, Brasil

\section{Comitê Editorial}

José Marcelino de Rezende Pinto - Universidade de São Paulo, Brasil

Juca Gil - Universidade Federal do Rio Grande do Sul, Brasil

Theresa Adrião - Universidade Estadual de Campinas, Brasil Ângelo

Ricardo de Souza - Universidade Federal do Paraná, Brasil

Márcia Aparecida Jacomini - Universidade Federal de São Paulo, Brasil

\section{Conselho Editorial}

\section{Alejandro Morduchowicz}

Universidad Pedagógica, Provincia de Buenos Aires, Argentina

Fernanda Saforcada

Universidade de Buenos Aires, Argentina

Jacques Velloso

Universidade de Brasília, Brasil

João Monlevade

Senado Federal, Brasil

Jorge Abrahão de Castro

Instituto de Pesquisa Econômica Aplicada / IPEA, Brasil

Juca Gil

Universidade Federal do Rio Grande do Sul, Brasil

Lisete Regina Gomes Arelaro

Universidade de São Paulo, Brasil

Luis Carlos Sales

Universidade Federal do Piauí, Brasil

Luiz de Sousa Junior

Universidade Federal da Paraíba, Brasil

Luiz Fernandes Dourado

Universidade Federal de Goiás, Brasil

Magna França

Universidade Federal do Rio Grande do Norte, Brasil

\section{Maria Beatriz Luce}

Universidade Federal do Pampa, Brasil

Universidade Federal do Rio Grande do Sul, Brasil

Marcos Edgar Bassi

Universidade Federal de Santa Catarina, Brasil

\author{
Maria Dilnéia Espíndola Fernandes \\ Universidade Federal de Mato Grosso do Sul, Brasil \\ Nalú Farenzena \\ Universidade Federal do Rio Grande do Sul, Brasil \\ Nelson Cardoso do Amaral \\ Universidade Federal de Goiás, Brasil \\ Nicholas Davies \\ Universidade Federal Fluminense, Brasil \\ Rosana Evangelista Cruz \\ Universidade Federal do Piauí, Brasil \\ Rosana Gemaque \\ Universidade Federal do Pará, Brasil \\ Robert E. Verhine \\ Universidade Federal da Bahia, Brasil \\ Romualdo Portela de Oliveira \\ Universidade de São Paulo, Brasil \\ Theresa Adrião \\ Universidade Estadual de Campinas, Brasil \\ Tristan McCowan \\ University of London, Reino Unido \\ Vera Jacob \\ Universidade Federal do Pará, Brasil \\ Vera Peroni \\ Universidade Federal do Rio Grande do Sul, Brasil \\ Vitor Henrique Paro \\ Universidade de São Paulo, Brasil
}

\section{Equipe editorial}

Apoio ao Comitê Editorial: Patrícia Balthazar Garcia

Diagramação, Revisão de português e normalização: Edson Leonel de Oliveira

Revisão de inglês: Ananyr Porto Fajardo 